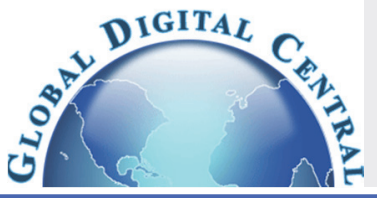

Frontiers in Heat and Mass Transfer

\title{
NON-LINEAR RADIATIVE FLOW OF NANOFLUID PAST A MOVING/STATIONARY RIGA PLATE
}

\author{
G.K. Ramesh ${ }^{\mathrm{a}, *}$ and B.J. Gireesha ${ }^{\mathrm{b}}$ \\ ${ }^{a}$ Department of Mathematics, School of Engineering, Presidency University, Bengaluru-560089, Karnataka, India. \\ ${ }^{b}$ Department of Studies and Research in Mathematics, Kuvempu University, Shankaraghatta-577 451, Shimoga, Karnataka, India
}

\begin{abstract}
The effect of non-linear thermal radiation on nanofluid flow over a riga plate is studied. Under some conditions, our problem reduces to the Blasius problem and Sakiadis problem. Similarity transformation is used to convert the governing steady Navier-Stokes equations into a system of coupled nonlinear differential equations, which are then solved numerically via Runge-Kutta-Fehlberg 45 order method along with a shooting method. Influence of parameters involved on velocity, temperature and concentration profiles is discussed with the help of graphical aid. Numerical results have been presented on the skin-friction coefficients, local Nusselt number and Sherwood number. It is found that in skin friction values of Blasius flow is higher than skin friction values of Sakiadis flow.
\end{abstract}

Keywords: Nanofluid, Blasius/Sakiadis problem, nonlinear thermal radiation, Riga plate, numerical solution.

\section{INTRODUCTION}

Incompressible two dimensional fluid flows over a stretching surface has a vital behavior on several technological applications in the field of metallurgy, chemical engineering and various manufacturing processes such as stretching of plastic films, metal spinning, metal extrusion, artificial fibers, glass blowing, spinning of fibers and continuous casting. In view of the above applications Blasius (1908) was the first who proposed the boundary layer flow on a flat plate. Sakiadis (1961) extended the work of Blasius (1908) and studied the quiescent fluid flow past a moving plate. Afzal et al. (1993) analyzed the combined study of Blasius problem and Sakiadis problem and converted into a single set of equations by introducing composite velocity. Bataller (2008) extended the work of Afzal et al. (1993) by studied the effects of radiation in presence of convective boundary condition. Later on the effect of thermal radiation on two dimensional flows past a moving plate with convective condition was investigated by Ishak et al. (2011). Mukhopadhyay et al. (2011) obtained the dual solution for radiative flow of a porous moving plate. Ramesh et al. (2015; 2016) examined the viscous flow past an inclined stationary/moving flat plate in the presence of convective condition. Further they extended the work of Ishak et al. (2011) by considering Williamson fluid.

Base fluids such as water, engine oil and ethylene glycol contain low thermal conductivity and metals have thermal conductivities up to three times superior than base fluids. Addition of nano sized metallic particles in the base fluids significantly increases the thermo physical characteristics of the base fluids. Therefore nanofluids are new invention of conventional fluids. Choi (1995) was the person introduced the term nanofluid and experimentally shown that the inclusion of nanometer sized particles in the base liquids it enhances the thermophysical characteristics of the base liquids. Buongiorno (2006) examined the behavior of thermophoresis and Brownian motion and developed a mathematical model for nanofluids. Khan and Pop (2010) was the first persons introduce the concept of nanofluid in boundary layer theory. Bachok et al (2012) extended work of Khan and Pop (2010) to Blasius and Sakiadis problems. Kandasamy et al. (2013) incorporate the radiation effect on nanofluids and obtained both exact and numerical solution. Ramesh and Gireesha (2014) examined the heat

*Corresponding Author. Email: gkrmaths@gmail.com source/sink effects on Maxwell nanofluid over a stretching sheet in the presence of convective condition. Some of the recent studies in this direction can be seen Shehzad et al. (2014); Prasannakumara et al. (2016); Ul Haq et al. (2015); Sheikholeslami (2015); Das et al. (2014); Ramesh and Gireesha (2013); Hayat et al. (2015); Rashidi et al; (2014), Pantokratoras and Fang (2013); Turkyilmazoglu and Pop (2013) and Makinde (2005) and references there in. Thermal radiation has potential role in manufacturing design of nuclear power plants and various engineering processes. Numerous researchers have paid their attention to address the mechanism of thermal radiation. Hayat et al. (2016) analyzed the impact of nonlinear radiative flow over convectively heated cylinder. Makinde and Animasaun (2016) studied the nonlinear thermal radiation effect on bioconvection nanofluid with quartic reaction. A comprehensive literature on nonlinear thermal radiation can be found in the references Hayat et al. (2016), and Ramesh et al. (2017).

Riga plate is an electromagnetic actuator comprises of permanent magnets and a spanwise aligned array of alternating electrodes mounted on a plane surface (Fig.1). Pantokratoras and Magyari (2009) constructed a basic equation for flow due to riga plate. Pantokratoras (2011) obtained the exact solutions for classical Blasius and Sakiadis problems over a Riga-plate. Further Magyari and Pantokratoras (2011) examined the convection effect on a viscous fluid over a Riga plate. Ahmad et al. (2016) obtained the analytical solution for nanofluid flow over a riga porous plate using perturbation method. Hayat et al. (2016) examined the flow of nanofluid over a Riga plate with variable thickness and convective condition.

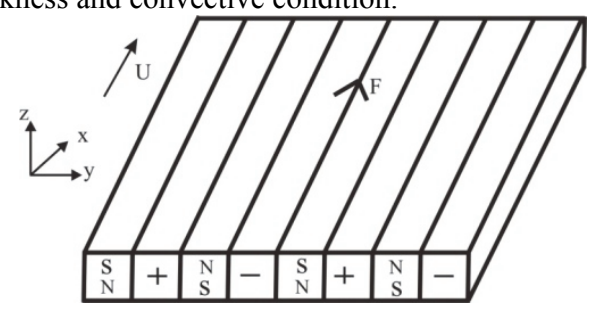

Fig. 1 Riga Plate

The present work we considered the composite velocity and studied the effect of nonlinear radiation on Nanofluid flow past a Riga plate. Similarity transforms are presented for this problem. The coupled nonlinear differential equations have been solved numerically by 
shooting method with fourth-fifth order Runge-Kutta (RK45). Present results are compared with the existing literature. To the best of our knowledge, this problem has not been studied before.

\section{MATHEMATICAL ANALYSIS}

We consider a laminar, steady two dimensional stretched flow of an electro-magneto hydrodynamic nanofluid over a Riga-plate. Assumed that the plate is moving with a constant velocity $U_{w}$ and that same or opposite direction to the free stream is $U_{\infty}$. Further assume that the surface has a uniform temperature $T_{w}$, ambient temperature $T_{\infty}$, uniform concentration $C_{w}$ and ambient concentration $C_{\infty}$ are respectively (see Fig. 2).

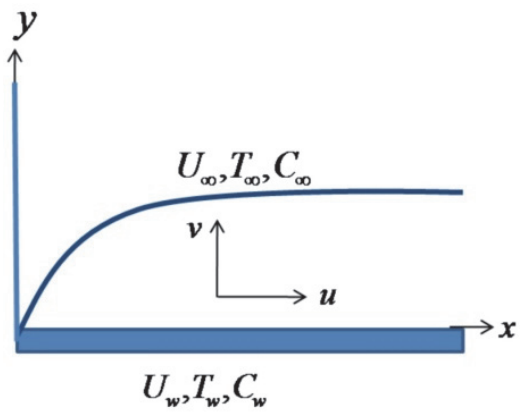

Fig. 2 Sketch of the problem and coordinate system.

With all the assumptions, mathematical equations of the nanofluid flow, the heat and the concentration fields are described in dimensional form as (see Ahmad et al. (2016))

$$
\begin{aligned}
& \frac{\partial u}{\partial x}+\frac{\partial v}{\partial y}=0 \\
& \left(u \frac{\partial u}{\partial x}+v \frac{\partial u}{\partial y}\right)=v \frac{\partial^{2} u}{\partial y^{2}}+\frac{\pi j_{0} M_{0}}{8 \rho} \exp \left(-\frac{\pi}{a} y\right) \\
& u \frac{\partial T}{\partial x}+v \frac{\partial T}{\partial y}=\alpha\left(\frac{\partial^{2} T}{\partial y^{2}}\right) \\
& \left\{D_{B}\left(\frac{\partial C}{\partial y} \frac{\partial T}{\partial y}\right)+\left(\frac{D_{T}}{T_{\infty}}\right)\left[\left(\frac{\partial T}{\partial y}\right)^{2}\right]\right\}-\frac{1}{\rho C_{p}} \frac{\partial q_{r}}{\partial y} \\
& u \frac{\partial C}{\partial x}+v \frac{\partial C}{\partial y}=D_{B}\left(\frac{\partial^{2} C}{\partial y^{2}}\right)+\left(\frac{D_{T}}{T_{\infty}}\right)\left[\left(\frac{\partial^{2} T}{\partial y^{2}}\right)\right]
\end{aligned}
$$

where $u$ and $v$ are the velocity components along the $x$ and $y$ axes, respectively. Further, $\alpha, \rho, v, T$ and $T_{\infty}$ are respectively the thermal diffusivity, density of the base fluid, kinematic viscosity of the fluid, fluid temperature and ambient fluid temperature. $j_{0}$ is the applied current density in the electrodes, $M_{0}$ is the magnetization of the permanent magnets mounted on the surface of the Riga plate, $a$ is the width of the magnets between the electrodes, $D_{B}$ is the Brownian diffusion coefficient, $D_{T}$ is the thermophoresis diffusion coefficient and $c_{p}$ is the specific heat at constant pressure. Here $\tau$ is defined as the ratio of the effective heat capacity of the nanoparticle material and the heat capacity of the ordinary fluid and $C$ is the concentration. The boundary conditions associated with the problem are $u=U_{w}(x), v=0, T=T_{w}, C=C_{w}$ at $y=0$

$u \rightarrow U_{\infty}, T \rightarrow T_{\infty}, C \rightarrow C_{\infty}$ as $y \rightarrow \infty$,
Expression of radiative heat flux can be defined, using Rosseland approximation is

$q_{r}=-\frac{4 \sigma^{*}}{3 k^{*}} \frac{\partial T^{4}}{\partial y}=\frac{16 \sigma^{*}}{3 k^{*}} T^{3} \frac{\partial T}{\partial y}$

where $\sigma^{*}$ is the Stefan-Boltzmann constant, $k^{*}$ is the mean absorption coefficient. Here in equation (6) $T$ is highly nonlinearity, and our main objective is to study the behavior of non-linear thermal radiation. Thus, using Pantokratoras and Fang (2013) the energy equation (3) will take the following form:

$$
\begin{aligned}
& u \frac{\partial T}{\partial x}+v \frac{\partial T}{\partial y}=\frac{\partial}{\partial y}\left[\left(\alpha+\frac{16 \sigma^{*}}{3 k^{*}} T^{3} \frac{\partial T}{\partial y}\right) \frac{\partial T}{\partial y}\right] \\
& +\tau\left\{D_{B}\left(\frac{\partial C}{\partial y} \frac{\partial T}{\partial y}\right)+\left(\frac{D_{T}}{T_{\infty}}\right)\left[\left(\frac{\partial T}{\partial y}\right)^{2}\right]\right\}
\end{aligned}
$$

Composite velocity is described as $U=U_{w}+U_{\infty}$ (Afzal et al. (1993)), we now introduce the similarity function $\psi$, which satisfies the governing continuity Eq. (1) as:

$$
u=\frac{\partial \psi}{\partial y} \text { and } v=-\frac{\partial \psi}{\partial x}
$$

and similarity solution of Eqs. (1),(2), (7) and (4) of the following form

$$
\begin{aligned}
& \eta=\sqrt{\frac{U}{v x}} y, \psi=\sqrt{U x v} f(\eta), \\
& \theta(\eta)=\frac{T-T_{\infty}}{T_{w}-T_{\infty}}, \phi(\eta)=\frac{C-C_{\infty}}{C_{w}-C_{\infty}},
\end{aligned}
$$

where $T=T_{\infty}\left(1+\left(\theta_{w}-1\right) \theta\right)$ and $\theta_{w}=\frac{T_{w}}{T_{\infty}}$ is the temperature ratio parameter (Shehzad et al. (2014)). Using the above relation (9) in Eqs. (2), (7) and (4), one can get the following non-dimensional equations

$$
\begin{aligned}
& f^{\prime \prime \prime}+\frac{1}{2} f f^{\prime \prime}+Q \exp (-\eta \beta) \\
& \left(\left[1+N r\left(1+\left(\theta_{w}-1\right) \theta\right)^{3}\right] \theta^{\prime}\right)^{\prime}+\operatorname{Pr}\left[\frac{1}{2} f \theta^{\prime}+N b \theta^{\prime} \phi^{\prime}+N t \theta^{2}\right]=0 \\
& \phi^{\prime \prime}+\frac{1}{2} f \phi^{\prime} S c+\frac{N t}{N b} \theta^{\prime \prime}=0
\end{aligned}
$$

Corresponding boundary conditions will becomes

$$
\left.\begin{array}{l}
f=0, f^{\prime}=\lambda, \theta=0, \phi=0 \text { at } \eta=0, \\
f^{\prime} \rightarrow 1-\lambda, \theta \rightarrow 0, \phi \rightarrow 0 \text { as } \eta \rightarrow \infty,
\end{array}\right\}
$$

Prime denotes the derivative with respect to $\eta$, and $Q$ is the modified Hartman number, $\beta$ is the dimensionless parameter, $N r$ is the radiation parameter, $N t$ is the thermophoresis parameter, $N b$ is the Brownian motion parameter, $S c$ is the Schmidt number, Pr is the Prandtl number and $\lambda$ is the velocity ratio parameter and they are defined as

$$
\begin{aligned}
& Q=\frac{x \mu j_{0} M_{0}}{8 \rho U^{2}}, \beta=\frac{\pi}{a(U / v x)^{1 / 2}}, N r=\frac{16 \sigma^{*} T_{\infty}^{3}}{3 k k^{*}}, N t=\frac{\tau D_{T}}{v T_{\infty}}\left(T_{w}-T_{\infty}\right), \\
& N b=\frac{\tau D_{B}}{v}\left(C_{w}-C_{\infty}\right), S c=\frac{v}{D_{B}}, \operatorname{Pr}=\frac{\alpha}{v}, \lambda=\frac{U_{w}}{U}
\end{aligned}
$$

As we note that when $\lambda=0$ the problem reduces to Blasius flow i.e., flow induced over a stationary flat-plate by a uniform free stream and when $\lambda=1$ the problem reduces to Sakiadis flow i.e., flow induced by a moving plate in a quiescent ambient fluid. The skin friction coefficient, local Nusselt number and local Sherwood number are the physical quantities defined as. 


$$
C_{f}=\frac{\tau_{w}}{\rho U_{w}^{2}}, N u_{x}=\frac{x q_{w}}{\alpha\left(T_{w}-T_{\infty}\right)}, S h_{x}=\frac{x q_{m}}{D_{B}\left(C_{w}-C_{\infty}\right)}
$$

where the shear stress $\tau_{w}$, surface heat flux $q_{w}$ and surface mass flux $q_{m}$ are given by

$$
\tau_{w}=\mu\left(\frac{\partial u}{\partial y}\right)_{y=0}, q_{w}=-\alpha\left(\frac{\partial T}{\partial y}\right)_{y=0} \text { and } q_{m}=-D_{B}\left(\frac{\partial C}{\partial y}\right)_{y=0}
$$

Using the non-dimensional variables, we obtain

$$
C_{f} \operatorname{Re}_{x}^{1 / 2}=f^{\prime \prime}(0), \frac{N u_{x}}{\operatorname{Re}_{x}^{1 / 2}}=-\left(1+N r \theta_{w}^{3}\right) \theta^{\prime}(0), \frac{S h_{x}}{\operatorname{Re}_{x}^{1 / 2}}=-\phi^{\prime}(0)
$$

\section{RESULTS AND DISCUSSION}

The coupled ordinary non-linear differential equations (10) to (12) along with the boundary conditions (13) were solved numerically using Runge-Kutta-Fehlberg 45 order method by adopting shooting technique [see Ramesh and Gireesha (2014)]. These equations are transformed into seven first order expressions involving fourteen unknowns. The missed initial conditions are found with help of shooting method. In order to validate our numerical solution, we have constructed Table 1. This table showed that comparative study of present results with the existing results. Impacts of various parameters on the velocity, temperature and concentration profiles are analyzed. Figs. 3-13 have been plotted in this regard.

Key parameter of the present study is modified Hartman number. Fig. 3 exhibits the effect of modified Hartman number $(Q)$ on the dimensionless velocity, temperature and concentration. It is clearly noted that the velocity profile of the nanofluid is significantly increased with increase of $Q$ whereas opposite effect are found in temperature and concentration. Physically large values of modified Hartman number results in the development of external electric field which consequently enhances the velocity distribution characteristics. Figs. 4 and 5 are prepared to shows the effect of $\beta$ on dimensionless velocity, temperature and concentration profiles. It is noticed that temperature and concentration of both profiles are significantly increases with the increasing of $\beta$ whereas opposite effect are found in velocity profile.

The behavior of Brownian motion parameter $\mathrm{Nb}$ on dimensionless temperature and concentration are plotted in Figs. 6 and 7. The temperature profile is increasing functions of Brownian motion number $\mathrm{Nb}$ whereas the concentration profile is decreasing function. Figs. 8 and 9 reveal the dimensionless temperature and concentration in response to a change in thermophoresis parameter $N t$. As increase of $N t$ values, the temperature and concentration boundary layer thickness is also increases. From Fig. 10, as Schmidt number Sc increases the concentration diagram decreases and also boundary layer thickness decreases. Further the graph reveals that the concentration gradient at surface is increases. Physical reason is larger values of Sc have a stronger viscous diffusion which increases the molecular motions hence the temperature increases.

Table-1: Comparison results of $f^{\prime \prime}(0)$ for different values of $\lambda$ in the absence of $S c, N b, N r, N t, \operatorname{Pr}, Q$ and $\beta$.

\begin{tabular}{|c|c|c|c|c|c|}
\hline$\lambda$ & $\begin{array}{l}\text { Blasius } \\
(1908)\end{array}$ & $\begin{array}{l}\text { Sakiadis } \\
(1961)\end{array}$ & $\begin{array}{l}\text { Ishak et } \\
\text { al. } \\
(2011)\end{array}$ & $\begin{array}{l}\text { Mukhopadhyay } \\
\text { et al. (2011) }\end{array}$ & $\begin{array}{l}\text { Present } \\
\text { results }\end{array}$ \\
\hline 0.0 & 0.332 & --- & 0.3321 & 0.332060 & 0.33205 \\
\hline 1.0 & --- & -0.4437 & -0.4438 & -0.443751 & -0.44390 \\
\hline
\end{tabular}
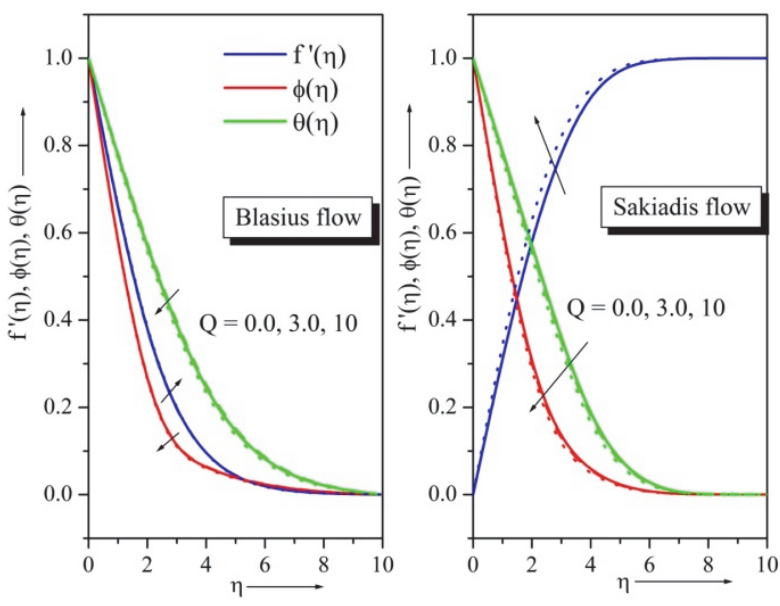

Fig. 3 Effect of $Q$ on velocity, temperature and concentration profiles

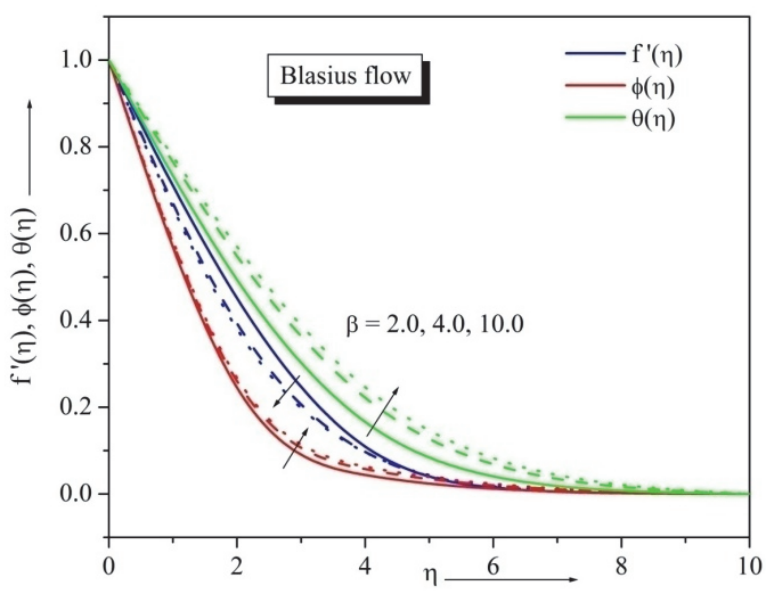

Fig. 4 Effect of $\beta$ on velocity, temperature and concentration profiles

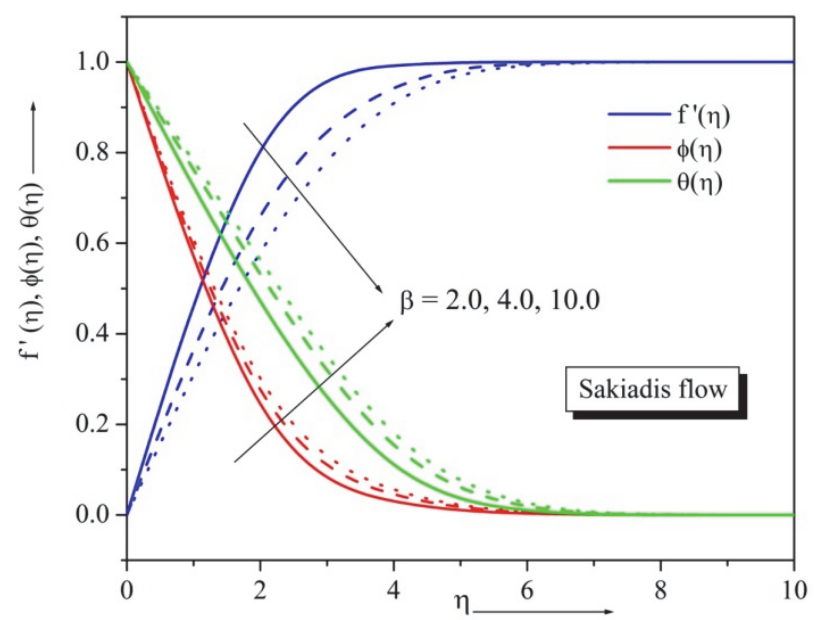

Fig. 5 Effect of $\beta$ on velocity, temperature and concentration profiles

Effects of radiation $\mathrm{Nr}$ on temperature profile is depicts in Fig. 11. One can observed that $\theta(\eta)$ shows the increasing behavior with increasing values of $N r$. And $\theta_{w}$ has to be larger value than one. Therefore, it is expected to have a higher temperature and a thicker thermal boundary layer with increasing values of $\theta_{w}$. 


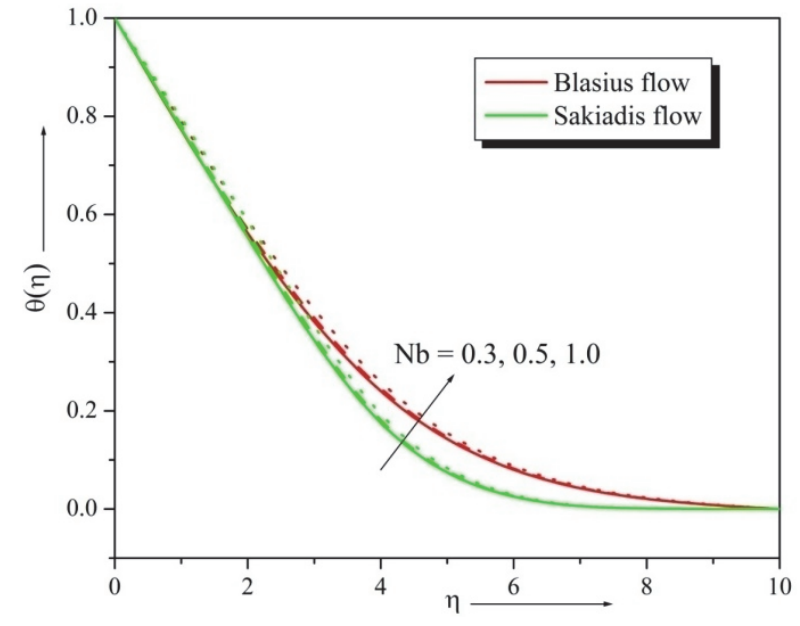

Fig. 6 Effect of $N b$ on temperature profile

The curves of temperature $\theta(\eta)$ for various Prandtl number are described in Fig. 12. We examined that the lower Prandtl number has higher profiles $\theta(\eta)$ and associated thickness of boundary layer. The diffusivity of liquid is appeared in Prandtl number that becomes weaker for higher Pr. The influence of velocity ratio parameter $\lambda$ on velocity, temperature and concentration profile are presented in Fig. 13. When we increasing the values of velocity ratio parameter simultaneously fluid velocity decreases, temperature increases and concentration decreases.

From Table 2 it is noted that $f^{\prime \prime}(0)_{\text {Blasius }}>f^{\prime \prime}(0)_{\text {Sakiadis }}$, $-\phi^{\prime}(0)_{\text {Blasius }}<-\phi^{\prime}(0)_{\text {Sakiadis }}$ and $-\theta^{\prime}(0)_{\text {Blasius }}<-\theta^{\prime}(0)_{\text {Sakiadis }}$

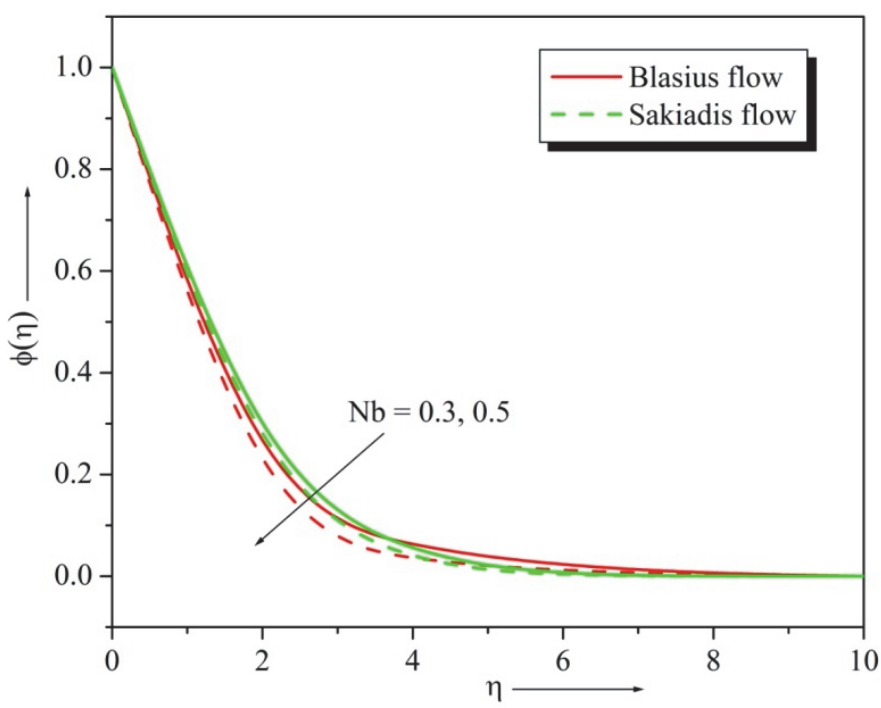

Fig. 7 Effect of $N b$ on concentration profile.

\section{CONCLUSIONS}

We study the behavior of nonlinear thermal radiation on a boundary layer flow of nanofluid over a Riga plate. Here we studied the two type problems namely classical Sakiadis flow (stationary plate) and Blasius flow (moving plate). The following points are worth mentioning.

- Velocity increases, temperature and concentration decreases when the modified Hartman number increases.

- Temperature increases when temperature ratio parameter increases.
- Increasing values of thermophoresis and Brownian motion parameters creates an enhancement in temperature profile because of higher thermal conductivity fluid.

- Skin friction values of Blasius flow always higher than the Sakiadis flow.

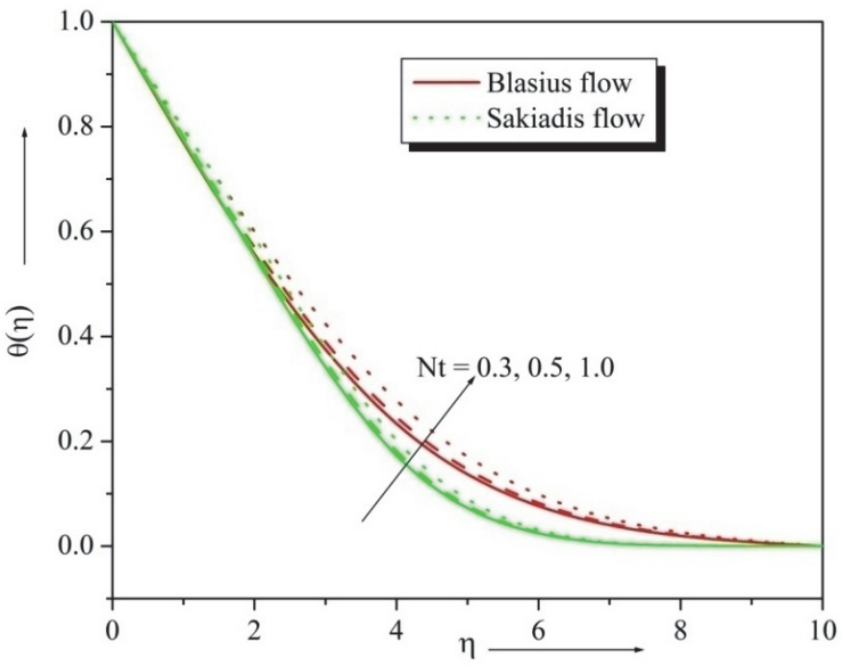

Fig. 8 Effect of $N t$ on temperature profile.

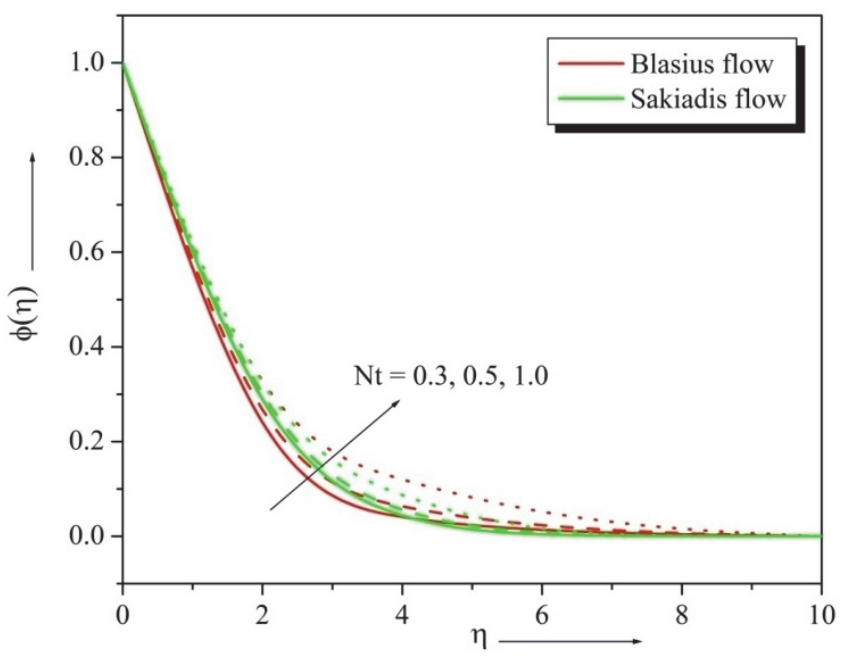

Fig. 9 Effect of $N t$ on concentration profile

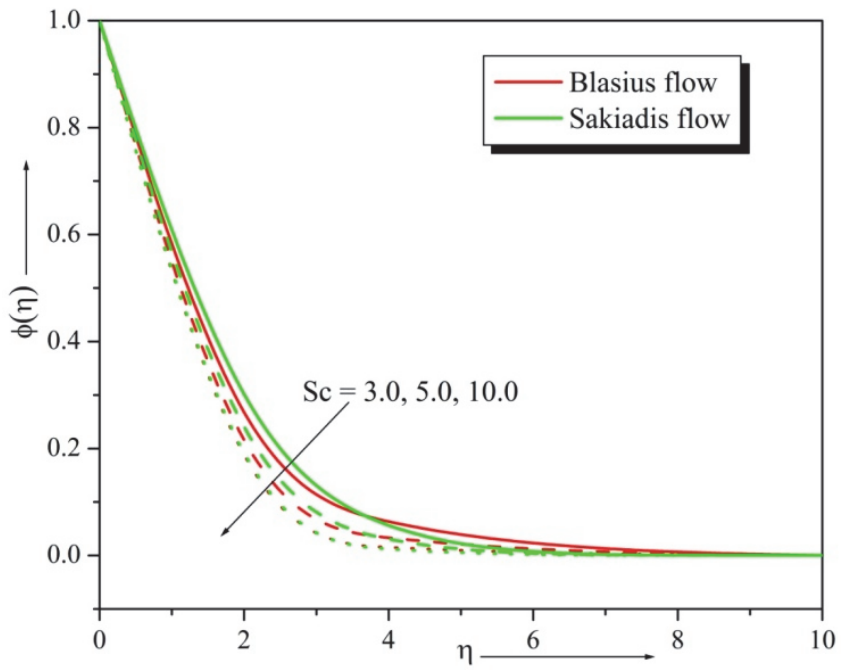

Fig. 10 Effect of $S c$ on concentration profile. 

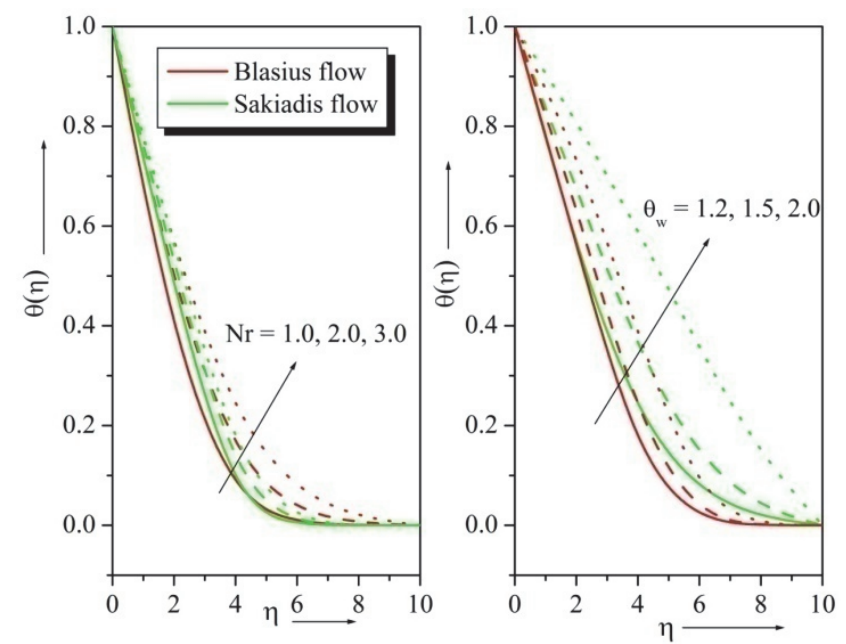

Fig. 11 Effect of $N r$ and $\theta_{w}$ on temperature profiles

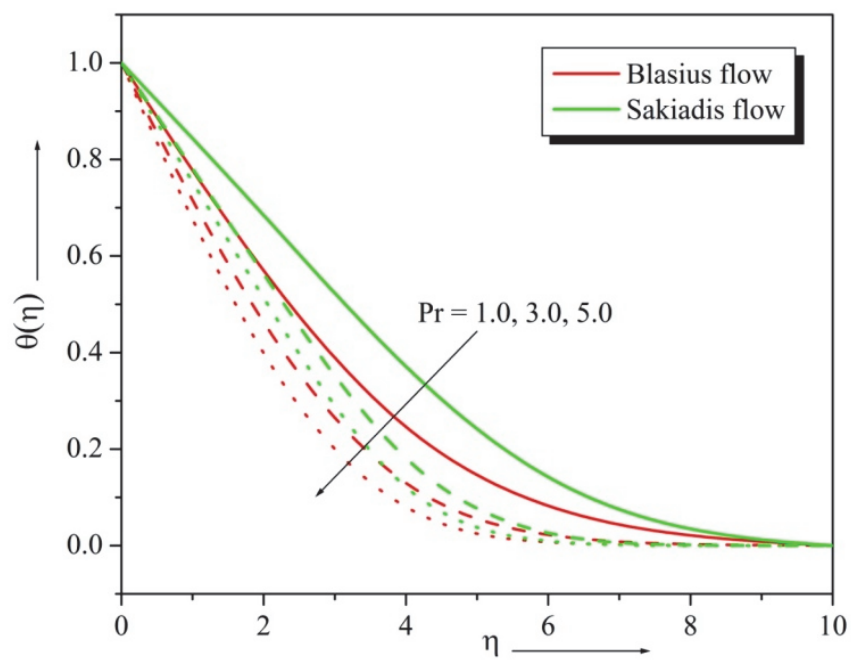

Fig. 12 Effect of $\operatorname{Pr}$ on temperature profile

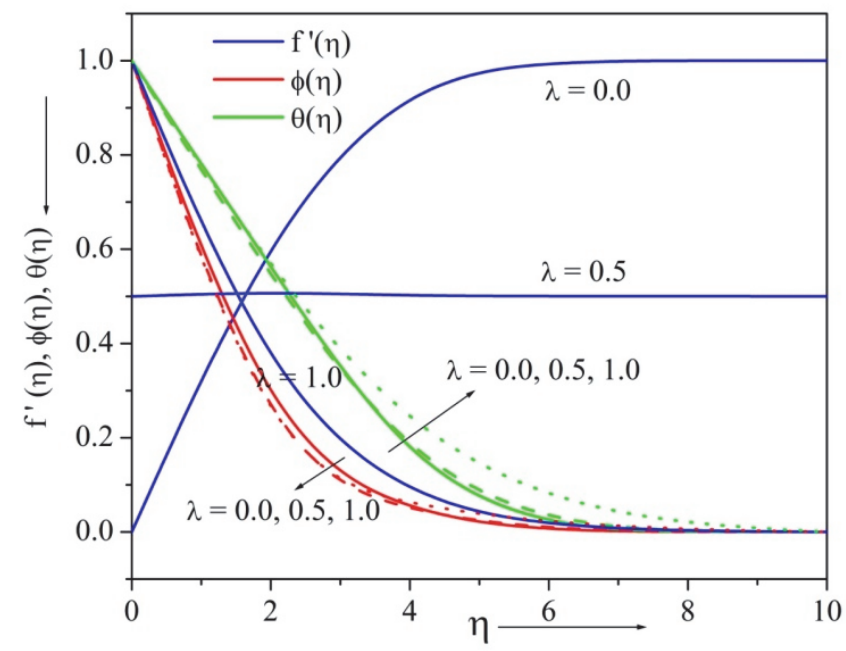

Fig. 13 Effect of $\lambda$ on velocity, temperature and concentration profiles

Acknowledgments: The authors are very much thankful to the editor and referee for their encouraging comments and constructive suggestions to improve the presentation of this manuscript. Also, one of the author G.K. Ramesh expresses sincere thanks to the Management of PRESIDENCY UNIVERSITY for their kind support.
Table-2: Computation Values of $-f^{\prime \prime}(0),-\theta^{\prime}(0)$ and $-\phi^{\prime}(0)$ for different values of $Q$ with $S c=3, N b=0.5, N r=3$, $N t=0.5, \operatorname{Pr}=3, \theta_{w}=1.2$ and $\beta=10$.

\begin{tabular}{|c|ccc|ccc|}
\hline & \multicolumn{3}{|c|}{ Sakiadis flow } & \multicolumn{3}{c|}{ Blasiaus flow } \\
\hline$Q$ & $-f^{\prime \prime}(0)$ & $-\phi^{\prime}(0)$ & $-\theta^{\prime}(0)$ & $f^{\prime \prime}(0)$ & $-\phi^{\prime}(0)$ & $-\theta^{\prime}(0)$ \\
\hline 0.0 & 0.44390 & 0.81143 & 0.18992 & 0.33205 & 0.50353 & 0.17043 \\
0.1 & 0.43449 & 0.81176 & 0.19000 & 0.34202 & 0.50411 & 0.17055 \\
0.5 & 0.39688 & 0.81308 & 0.19034 & 0.38188 & 0.50642 & 0.17105 \\
0.8 & 0.36867 & 0.81407 & 0.19059 & 0.41176 & 0.50814 & 0.17141 \\
1.0 & 0.34986 & 0.81472 & 0.19076 & 0.43168 & 0.50929 & 0.17166 \\
\hline
\end{tabular}

\section{NOMENCLATURE}

a width of the magnets between the electrodes

$c \quad$ Concentration $\left(\mathrm{kg} / \mathrm{m}^{3}\right)$

$c_{p} \quad$ Specific heat $(J / k g K)$

$c_{w} \quad$ concentration at wall

$c_{\infty} \quad$ ambient concentration

$D_{B} \quad$ Brownian diffusion coefficient

$D_{T} \quad$ thermophoresis diffusion coefficient

$f$ dimensionless stream function

$j_{0} \quad$ applied current density in the electrodes

$k$ thermal conductivity $(\mathrm{W} / \mathrm{mK})$

$k^{*} \quad$ mean absorption coefficient $\left(m^{-1}\right)$

$M_{0} \quad$ magnetization of the permanent magnets

$\mathrm{Nr} \quad$ radiation parameter

$\mathrm{Nb} \quad$ Brownian motion parameter

Nt thermophoresis parameter

Pr Prandtl number

$Q \quad$ modified Hartman number

Sc Schmidt number

$T \quad$ temperature of the fluid $(K)$

$T_{w} \quad$ uniform temperature $(K)$

$T_{\infty} \quad$ ambient temperature $(K)$

$U_{w} \quad$ constant velocity

$U_{\infty} \quad$ free stream velocity

$u, v \quad$ velocity components of the fluid along $x$ and $y$ directions

$x, y \quad$ Cartesian co-ordinates

\section{Greek Symbols}

$\alpha \quad$ thermal diffusivity $\left(\mathrm{m}^{2} / \mathrm{s}\right)$

$\beta \quad$ dimensionless parameter

$\lambda \quad$ velocity ratio parameter

$\rho \quad$ density of the base fluid $\left(\mathrm{kg} / \mathrm{m}^{3}\right)$

$v \quad$ kinematic viscosity of the fluid $\left(\mathrm{m}^{2} / \mathrm{s}\right)$

$\sigma^{*} \quad$ Stefan-Boltzmann constant $\left(W / m^{2} K^{4}\right)$

$\theta \quad$ dimensionless fluid temperature

$\theta_{w} \quad$ temperature ratio parameter

$\mu \quad$ viscosity of the fluid $\left(\mathrm{N} s / \mathrm{m}^{2}\right)$

$\eta \quad$ similarity variable

\section{Subscripts}

w at the wall

$\infty \quad$ ambient temperature 


\section{REFERENCES}

Afzal, N., Badaruddin, A., and Elgarvi, A.A., 1993, "Momentum and Transport on a Continuous Flat Surface Moving in a Parallel Stream", Int. J. Heat Mass Transf., 36,3399-3403. http://dx.doi.org/10.1016/0017-9310(93)90022-X

Ahmad, A., Asghar, S., and Afzal, S., 2016, "Flow of Nanofluid Past a Riga Plate", J. Magnetism and Magnetic Materials, 402, 44- 48. http://dx.doi.org/10.1016/i.jmmm.2015.11.043

Blasius, H., 1908, "Grenzschichten in Flüssigkeiten mit Kleiner Reibung”, Zeitschrift für Mathematik und Physik, 56, 1-37.

Bataller, R.C., 2008, "Radiation Effects for the Blasius and Sakiadis Flows with a Convective Surface Boundary Condition”, Appl. Math. Comput., 206, 832-840.

http://dx.doi.org/10.1016/j.amc.2008.10.001

Buongiorno, J., 2006, "Convective Transport in Nanofluids". ASME Journal of Heat Transfer, 128, 240-250.

doi:10.1115/1.2150834

Bachok, N., Ishak A., and Pop, I., 2012, "Flow and Heat Transfer Characteristics on a Moving Plate in a Nanofluid", Int. J. Heat and Mass Transf., 55, 642-648.

http://dx.doi.org/10.1016/j.ijheatmasstransfer.2011.10.047

Choi, S.U.S., 1995, "Enhancing Thermal Conductivity of Fluids with Nanoparticles", ASME 66, 99-105. USA, FED 231/MD.

Das, K., Duari, P.R., and Kundu, P.K., 2014, "Solar Radiation Effects on $\mathrm{Cu}$-Water Nanofluid Flow Over a Stretching Sheet with Surface Slip and Temperature Jump", Arab J. Sci. Eng., 39, 9015-9023.

https://doi.org/10.1007/s13369-014-1380-4

Hayat, T., Abbas, T., Ayub, M., Farooqc, M., and Alsaedi, A., 2016 "Flow of Nanofluid Due to Convectively Heated Riga Plate with Variable Thickness", J Molecular Liquids, 222, 854-862.

http://dx.doi.org/10.1016/j.molliq.2016.07.111

Hayat, T., Muhammad, T., Alsaedi, A., and Alhuthali, M.S., 2015, "Magnetohydrodynamic Three-Dimensional Flow of Viscoelastic Nanofluid in the Presence of Nonlinear Thermal Radiation", J. Magn. Magn. Mater., 385, 222-229.

http://dx.doi.org/10.1016/i.jmmm.2015.02.046

Hayat, T., Tamoor, M., Khan, M.I., and Alsaedi, A., 2016, Numerical Simulation for Nonlinear Radiative Flow by Convective Cylinder, Results in Physics, 6, 1031-1035.

https://doi.org/10.1016/j.rinp.2016.11.026

Hayat, T., Qayyum, S., Alsaedi, A., and Shehzad, S.A., 2016, Nonlinear Thermal Radiation Aspects in Stagnation Point Flow of Tangent Hyperbolic Nanofluid with Double Diffusive Convection, $J$. Molecular Liquids, 223, 969-978.

https://doi.org/10.1016/i.molliq.2016.08.102

Ishak, A., Yacob, N.A., and Bachok, N., 2011, "Radiation Effects on the Thermal Boundary Layer Flow Over a Moving Plate With Convective Boundary Condition”, Meccanica, 46, 795-801.

https://doi.org/10.1007/s11012-010-9338-4

Khan, W.A., and Pop, I., 2010, "Boundary-Layer Flow of a Nanofluid Past a Stretching Sheet". Int. J Heat and Mass Transf., 53(11),24772483.

http://dx.doi.org/10.1016/j.ijheatmasstransfer.2010.01.032
Kandasamy, R., Muhamin, I., and Mohamad, R., 2013, "Thermophoresis and Brownian Motion Effects on MHD BoundaryLayer Flow of a Nanofluid in the Presence of Thermal Stratification Due to Solar Radiation". Int. J Mech. Sci., 70, 146-154.

http://dx.doi.org/10.1016/j.ijmecsci.2013.03.007

Mukhopadhyay, S., Bhattacharyya, K., and Layek, G.C., 2011, "Steady Boundary Layer Flow and Heat Transfer Over a Porous Moving Plate in Presence of Thermal Radiation", Int. J. Heat and Mass Transfer, 54, 2751-2757.

http://dx.doi.org/10.1016/j.ijheatmasstransfer.2011.03.017

Makinde, O.D., 2005, "Free Convection Flow with Thermal Radiation and Mass Transfer Past a Moving Vertical Porous Plate", Int. Comm. in Heat and Mass Transfer, 32 (10), 1411-1419.

http://dx.doi.org/10.1016/j.icheatmasstransfer.2005.07.005

Makinde, O.D., and Animasaun, I.L., 2016, Thermophoresis and Brownian Motion Effects on MHD Bioconvection of Nanofluid with Nonlinear Thermal Radiation and Quartic Chemical Reaction Past an Upper Horizontal Surface of a Paraboloid of Revolution, J. Molecular liquids, 221, 733-743.

https://doi.org/10.1016/j.molliq.2016.06.047

Magyari, E., and Pantokratoras, A., 2011, "Aiding and Opposing Mixed Convection Flows Over the Riga-Plate", Commun Nonlinear Sci Numer Simulat., 16, 3158-3167.

http://dx.doi.org/10.1016/j.cnsns.2010.12.003

Pantokratoras, A., and Fang, T., 2013, "Sakiadis Flow With Nonlinear Rosseland Thermal Radiation". Phys. Scr., 87(1), 015703.

https://doi.org/10.1088/0031-8949/87/01/015703

Prasannakumara, B.C., Gireesha, B.J., Gorla, R.S.R., and Krishnamurthy, M.R., 2016, "Effects of Chemical Reaction and Nonlinear Thermal Radiation on Williamson Nanofluid Slip Flow over a Stretching Sheet Embedded in a Porous Medium". J. Aerosp. Eng., 29(5). 04016019.

https://doi.org/10.1061/(ASCE)AS.1943-5525.0000578

Pantokratoras, A., and Magyari, E. , 2009, "EMHD Free-Convection Boundary-Layer Flow From a Riga-Plate", J. Eng. Maths., 64 (3), $303-$ 315 .

https://doi.org/10.1007/s10665-008-9259-6

Pantokratoras, A., 2011, "The Blasius and Sakiadis Flow Along a Riga-Plate", Progress in Computational Fluid Dynamics, 11(5), 329333.

http://dx.doi.org/10.1504/PCFD.2011.042184

Ramesh, G.K., Chamkha, A.J., and Gireesha, B.J., 2016, "Boundary Layer Flow Past an Inclined Stationary/Moving Flat Plate with Convective Boundary Condition", Afrika Matematika, 27, 87-95.

https://doi.org/10.1007/s13370-015-0323-x

Ramesh, G.K., Gireesha, B.J., and Gorla, R.S.R., 2015, "Study on Sakiadis and Blasius Flow of Williamson Fluid with Convective Boundary Condition", Nonlinear Engineering, 4(4), 215-221. https://doi.org/10.1515/nleng-2015-0020,

Rashidi, M.M., Rostami, B., Freidoonimehr, N., and Abbasbandy, S., 2014, "Free Convective Heat and Mass Transfer for MHD Fluid Flow Over a Permeable Vertical Stretching Sheet in the Presence of the Radiation and Buoyancy Effects", Ain Shams Eng. J. 5, 901-912. http://dx.doi.org/10.1016/j.asej.2014.02.007

Ramesh, G.K., and Gireesha, B.J., 2014, "Influence of Heat Source/Sink on a Maxwell Fluid Over a Stretching Surface with 
Convective Boundary Condition in the Presence of Nanoparticles", Ain Shams Engineering Journal, 5, 991-998.

http://dx.doi.org/10.1016/j.asej.2014.04.003

Ramesh, G.K., and Gireesha, B.J., 2013, "Flow Over a Stretching Sheet in a Dusty Fluid with Radiation Effect", ASME J. Heat transfer, 135(10) $102702(1-6)$.

doi. $10.1115 / 1.4024587$

Ramesh, G.K., Prasannakumara, B.C., Gireesha, B.J., Shehzad, S.A., and Abbasi, F.M., 2017, Three Dimensional Flow of Maxwell Fluid with Suspended Nanoparticles Past a Bidirectional Porous Stretching Surface with Thermal Radiation, Thermal Science and Engineering Progress, 1, 6-14.

https://doi.org/10.1016/j.tsep.2017.02.006

Sakiadis, B.C., 1961, "Boundary-Layer Behaviour on Continuous Solid Surfaces: Boundary-Layer Equations for Two Dimensional and Axisymmetric Flow", AIChE J. 7, 26-28.

doi. 10.1002/aic.690070108

Shehzad, S.A., Hayat, T., Alsaedi, A., and Obid, M.A., 2014, "Nonlinear Thermal Radiation in Three-Dimensional Flow of Jeffrey
Nanofluid: A Model for Solar Energy", Appl. Math. Comput., 248, 273286.

http://dx.doi.org/10.1016/j.amc.2014.09.091

Sheikholeslami, M., Ganji, D.D., Javed, M.Y., and Ellahi, R., 2015, "Effect of Thermal Radiation on Magnetohydrodynamics Nanofluid Flow and Heat Transfer by Means of Two Phase Model", J. Magn. Magn. Mater., 374,36-43.

http://dx.doi.org/10.1016/j.jmmm.2014.08.021

Turkyilmazoglu, M., and Pop, I., 2013, "Heat and Mass Transfer of Unsteady Natural Convection Flow of Some Nanofluids Past a Vertical Infinite Flat Plate with Radiation Effect", Int. J. Heat Mass Transfer, 59, 167-171.

http://dx.doi.org/10.1016/j.ijheatmasstransfer.2012.12.009

Ul Haq, R. , Nadeem, S., Khan, Z.H., and Akbar, N.S., 2015, “Thermal Radiation and Slip Effects on MHD Stagnation Point Flow of Nanofluid Over a Stretching Sheet", Physica E: Low-dimensional Systems and Nanostructures, 65,17-23.

http://dx.doi.org/10.1016/j.physe.2014.07.013 